\title{
Failure to Detect a Stimulatory Effect of Estradiol-17 $\beta$ on Ovine Fetal Lung Maturation
}

\author{
OSCAR ANDUJO, CHARLES R. ROSENFELD, HEBER C. NIELSEN, C. RICHARD PARKER, JR., \\ AND JEANNE M. SNYDER \\ Departments of Pediatrics, Obstetrics-Gynecology, and Cell Biology and Anatomy and The Cecil H. \& Ida Green \\ Center for Reproductive Biology Sciences, The University of Texas Health Science Center at Dallas,
}

Southwestern Medical School, Dallas, Texas 75235

\begin{abstract}
It has been reported that estradiol-17 $\beta$ (E2) stimulates rat and rabbit fetal lung maturation; however, E2 was not directly administered to the fetus in these experiments. Therefore, we used the chronically instrumented fetal sheep to study the effects of 14 days of continuous E2 infusion on fetal lung maturation. Animals were instrumented on days 104-106 of gestation, then infused with either saline or E2 $(100 \mu \mathrm{g} /$ day $)$ from 111 to 127 days of gestation. Fetal plasma concentrations of E2, estrone, and cortisol, and tracheal fluid phosphatidylcholine:sphingomyelin ratios and phosphatidylcholine flux were measured daily in E2-infused $(n=8)$ and salineinfused $(n=6)$ control animals. At 127 days of gestation, fetuses were sacrificed and lung tissue samples obtained for biochemical and morphological analyses. Plasma E2 levels rose from $0.045 \pm 0.001(\overline{\mathrm{x}} \pm \mathrm{SE})$ to $7.45 \pm 5.31$ $\mathrm{ng} / \mathrm{ml}(p<0.05)$ in E2-infused animals whereas levels remained $<0.06 \mathrm{ng} / \mathrm{ml}$ in saline-infused animals. Plasma estrone concentrations also were significantly elevated by E2 infusion. Plasma contisol concentrations increased from $0.58 \pm 0.08$ to $0.88 \pm 0.40 \mu \mathrm{g} / \mathrm{dI}$ in E2-treated fetuses during the last week of infusion whereas values in control animals were unchanged. The ratio of acetone-precipitated phosphatidylcholine to sphingomyelin and the flux of acetone-precipitated phosphatidylcholine in tracheal fluid were not affected by $\mathrm{E} 2$ infusion. Fetal lung tissue phospholipid content was also unaffected by E2 infusion. Furthermore, there was no consistent effect of E2 infusion on the histological structure of the fetal lung tissue as determined by morphometric methods. Therefore, we conclude that prolonged elevations in plasma $\mathrm{E} 2$ in the early to middle 3rd trimester of gestation, i.e., prior to 128 days of gestation, do not stimulate lung maturation in the intact ovine fetus. (Pediatr Res 22: 145-149, 1987)
\end{abstract}

\section{Abbreviations}

RDS, respiratory distress syndrome

E2, estradiol-17 $\beta$

PC, phosphatidylcholine

E1, estrone

iv, intravenous

RIA, radioimmunoassay

DSPC, disaturated phosphatidylcholine

$\mathrm{S}$, sphingomyelin

Received July 8, 1986; accepted February 25, 1987

Supported, in part, by NIH Grants HD13912, HD08783, HD14513, HL32650, and HL29722

Correspondence and requests for reprints, Dr. Jeanne M. Snyder, Department of Cell Biology and Anatomy, University of Texas Health Science Center, 5323 Harry Hines Boulevard, Dallas, TX 75235.
RDS of the newborn is caused by inadequate surfactant production by type II cells of the lung alveolus (1). However, the factor(s) responsible for the regulation of fetal lung maturation remains unclear. A better understanding of the mechanisms which regulate fetal lung maturation might lead to better treatments to prevent or ameliorate neonatal RDS. It is now well documented that the differentiation of the fetal lung type II cell can be accelerated by treatment of the fetus or the mother with various hormones (2). Several investigators have suggested that estrogens might play a role in fetal lung maturation. The fetal and maternal plasma concentrations of estrogen not only rise during the last half of human gestation $(3,4)$, but this rise in estrogen levels precedes the increase in surfactant production by fetal lung. Furthermore, low levels of urinary and umbilical cord blood estrogens in neonates have been reported to correlate positively with an increased incidence of $\operatorname{RDS}(5,6)$.

Khosla and coworkers $(7,8)$ have reported that injection of pregnant rabbits with $75 \mu \mathrm{g} /$ day of estradiol- $17 \beta$ resulted in a stimulation of lung phosphatidylcholine content and choline incorporation into PC of fetal lung slices. Estrogen administration to the pregnant doe also resulted in the increased activity of fetal lung cholinephosphate cytidylyltransferase, an enzyme that may be rate limiting in the synthesis of PC (9). Gross et al. (10) also have reported that treatment of fetal rat lung explants in organ culture with $10^{-5} \mathrm{M}$ estrogen results in increased incorporation of $\left[{ }^{3} \mathrm{H}\right]$ acetate into $\mathrm{PC}$ and phosphatidylglycerol (10). Recently, Thuresson-Klein et al. (11) have reported a marked stimulation of fetal rat lung type II cell differentiation by estrogen injection into the amniotic sac. Thus, there is considerable evidence, obtained from studies using various animal models, both in vivo and in vitro, that estrogen can stimulate differentiation of fetal lung type II cells.

In most of the in vivo studies cited above, relatively large amounts of estrogen were used and in most instances the estrogen was administered to the mother. The resulting fetal plasma estrogen concentrations were not determined in these studies. Although some maternally administered estrogen (i.e. estradiol) may cross the placenta, the placenta has been shown to be relatively impermeable to transplacental transport of estrogens (12); furthermore, transplacental estrogen reaching the fetus is either rapidly conjugated, converted to E1, a weak estrogen, or rapidly cleared by the fetal placenta $(12-15)$. Therefore, we used the chronically instrumented fetal sheep to study the effects of prolonged fetal estrogen infusion on several aspects of the differentiation of the fetal lung type II cell. We determined that, in this species, prolonged elevation of fetal plasma unconjugated estrogen prior to the surge of surfactant synthesis and release that occurs late in gestation $(16,17)$ does not affect the differentiation of the fetal lung type II cell.

\section{MATERIALS AND METHODS}

Animals. Fourteen pregnant ewes of mixed Western breed were studied between the 106th and 127th days of gestation. 
There were 12 singleton and two twin pregnancies. The surgical procedures used in this study have been described in detail previously $(17,18)$. Briefly, using sterile techniques and under spinal anesthesia supplemented with iv pentobarbitol $(15 \mathrm{mg} /$ $\mathrm{kg}$ ), polyvinal catheters were inserted on the 104-106th days of gestation into the fetal trachea after ligation and the fetal femoral artery and vein. The tracheal catheter was attached to a soft plastic bag of $300 \mathrm{ml}$ capacity which was placed into the amniotic sac, providing a reservior for the continuous collection of tracheal fluid. A second catheter attached to the reservoir was exteriorized for the purpose of sampling. After closing the uterine incisions and maternal abdomen, catheters were implanted in the maternal femoral artery and vein. All catheters were brought out to the flank through a subcutaneous tunnel and maintained in a canvas pouch attached to the skin with steel pins. Each animal was returned to the laboratory and maintained in a separate stall with water and feed allowed ad libitum throughout the study period. The catheters were flushed daily with $0.15 \mathrm{M} \mathrm{NaCl}$ containing 250 and $500 \mathrm{U} / \mathrm{ml}$ of heparin for the maternal and fetal catheters, respectively. The catheters were sealed with sterile pins. Penicillin $(600,000 \mathrm{U})$ and streptomycin $(0.5 \mathrm{~g})$ were given to the mother on the day of surgery and for the next 2 postoperative days. The fetus received $50 \mathrm{mg}$ of Ampicillin iv every other day throughout the experiment. All of the fetuses included in the study remained healthy as determined by intermittent measurement of arterial blood gases, heart rate, and mean arterial pressure. The pregnant ewe was monitored in a similar fashion. Premature labor did not occur in any of the animals included in this study.

Experimental protocol. In eight animals, E2 (Steraloids, Inc., Pawling, NY) was infused constantly through the femoral venous catheter of the fetus with a Harvard constant infusion pump at a rate of $100 \mu \mathrm{g} /$ day beginning on day 111 of gestation (i.e at least 5 days postoperatively) and terminating on the 127th day of pregnancy. The dose of E2 was chosen to achieve plasma levels of unconjugated estrogens substantially greater than that normally seen in the fetal sheep remote from term and close to those observed at term in the fetal sheep (19). The concentration of the infusate was $100 \mu \mathrm{g}$ of E2/ml and consisted of $0.9 \mathrm{ml}$ of sterile $0.15 \mathrm{M} \mathrm{NaCl}$ and $0.1 \mathrm{ml}$ of a stock solution of $\mathrm{E} 2$ in ethanol $(1 \mathrm{mg} / \mathrm{ml})$. Control animals $(n=6)$ were infused with $0.15 \mathrm{M} \mathrm{NaCl}$ at the same rate and volume. Using sterile precautions, tracheal fluid samples were collected daily before and during the infusion period by emptying the tracheal reservoir at approximately the same time of day, between 0900 and $1200 \mathrm{~h}$. The tracheal fluid samples were collected into chilled plastic syringes then transferred to glass tubes and immediately centrifuged at $700 \times g$ for $5 \mathrm{~min}$ to remove cells and debris. The supernate was frozen at $-20^{\circ} \mathrm{C}$ until the time of assay. Heparinized blood samples $(3.0 \mathrm{ml})$ were collected daily in sterile syringes for the first 5 days postoperative and every other day beginning on day 111 of gestation from the fetal femoral artery catheter and the plasma, immediately separated from red blood cells, which were resuspended in sterile saline and returned to the fetus (18). An additional $1.0 \mathrm{ml}$ of unheparinized blood was obtained in a similar manner and the serum separated from the red blood cells and the clot. All plasma samples were frozen at $-20^{\circ} \mathrm{C}$ until assay.

At the end of the infusion period (day 127 of gestation) the ewe was anesthetized with iv ketamine $(10 \mathrm{mg} / \mathrm{kg})$ supplemented with iv pentobarbitol. The fetus was delivered by cesarian section and sacrificed immediately by injection of sodium pentobarbitol $(300 \mathrm{mg} / \mathrm{ml})$ into the femoral venous catheter. The mother then was sacrificed by rapid injection of $12 \mathrm{ml}$ of the sodium pentobarbitol solution into the femoral venous catheter. Tissue samples were obtained from the right upper lobe of the lung of the mother and fetus and were fixed in glutaraldehyde $(2.5 \%)$ for morphological analysis. Lung tissue samples also were taken for phospholipid analysis. At the time of sacrifice, the mean fetal weights $( \pm$ SD) of control and E2-treated fetuses were $2498 \pm 414$ and $2033 \pm 673$, respectively, and the male to female ratios were
1:5 and 1:7, respectively. The weights of control and E2-treated fetuses were not statistically different $(p=0.17)$; the lower mean weight in the experimental animals is reflective of two twin fetuses.

Assays. Plasma samples were assayed for unconjugated E1 and total unconjugated estradiol (estradiol-17 $\alpha$ plus E2 $\beta$ ) by RIA using an antibody that measures both the $17 \alpha$ and $17 \beta$ epimers of E2 (20). $17 \beta$-E2 reacts $100 \%$ and $17 \alpha$-E2 cross reacts $14 \%$ with the antiserum. The validation for the determinations of E1 and E2 by RIA in ovine plasma has been reported (18). Cortisol was measured using a slight modification of a RIA method previously described (21). Tritiated, rather than iodinated cortisol was used as the assay tracer; nonantibody-bound tracer was separated from antibody-bound tracer by use of a suspension of dextran-coated charcoal. The intra- and interassay coefficients of variation were less than $10 \%$. With the dilution and assay volumes used, the least detectable amount of cortisol was $0.1 \mu \mathrm{g} / \mathrm{dl}$.

Phospholipid analysis. Lung tissue samples were obtained from three control and three E2-treated fetuses, homogenized in distilled water, and an aliquot removed for protein determination using the method of Lowry et al. (22). Aliquots of the tissue homogenates were extracted using chloroform-methanol (23). The proportion of DSPC in the lipid extract was determined using the method of Mason et al. (24). The amount of lipid phosphorous was determined using a colorimetric assay (25).

Tracheal fluid samples were also extracted using chloroformmethanol as described above, followed by acetone precipitation as described by Gluck et al. (26). The acetone-precipitated fraction was dissolved in chloroform, applied to thin-layer silica gel H sheets (Eastman Kodak 13179, Eastman Kodak Co., Rochester, NY) and the phospholipids separated employing the solvent system chloroform:methanol:water $(65: 35: 4)$. Following chromatography, the thin-layer plates were dried in air, the phospholipids localized by exposure to iodine vapors and scraped. PC and $\mathrm{S}$ were then quantitated by assaying for inorganic phosphorus (25). The data are expressed as the ratio of acetone-precipitated $\mathrm{PC} / \mathrm{S}$ and as the flux of acetone-precipitated phosphatidylcholine $(\mu \mathrm{g} / \mathrm{h})$.

Morphology. Lung tissues were also fixed and embedded for electron microscopy using methods described previously (27). The right upper lobe was quickly sliced into $1-\mathrm{mm}$ fragments with a razor blade, fixed in glutaraldehyde $(2.5 \%)$ in phosphate buffer $(0.1 \mathrm{M}, \mathrm{pH} 7.4)$, and embedded in plastic resin. Representative $1-\mu$ thick sections from each animal were cut with glass knives then stained with toluidine blue. These sections were used for a morphometric analysis of changes in the relative amount of epithelium, connective tissue, blood vessels, and lumen in the fetal lung tissue. Three thick sections, obtained from three different pieces of tissue, from each animal were then analyzed at $400 \times$ with a light microscope containing an eyepiece grid with 100 point intersections. Only areas of peripheral lung were examined, areas which included large airways or large blood vessels were not scored. Each point on the grid was scored as to its location on lumen, epithelium, blood vessel, or connective tissue. Three areas, chosen at random, were analyzed on each section (100 points/area, total of 300 points per section). The data are expressed as the volume density (\%), or proportion of the tissue volume, occupied by each component.

Statistical methods. In order to compare the results of these studies with those previously reported from our laboratories (17), the data for maternal and fetal hormones and fetal tracheal phospholipids were grouped into 5-day intervals, beginning at 106 days of gestation (except for the last time point which represents a 2-day interval, i.e. days 126 and 127 of gestation). The average of all measurements during each interval for each animal was utilized to determine the mean and SE for all animals in each 5-day period. Differences between control and estrogentreated animals were evaluated by repeated measures of two-way analysis of variance, with Newman-Keuls comparisons to identify differences at specific points (28). The relationship between 
plasma estrogen (E2 and E1) and tracheal PC flux and the PC/S ratio was evaluated by linear regression analysis. The morphometric data and tissue phospholipid data were compared using Student's unpaired $t$ test (28). Data are presented as the mean and SEM.

\section{RESULTS}

Hormones. We determined the fetal plasma concentrations of unconjugated estrogen in five of the saline-infused controls and seven of the E2-infused fetal sheep throughout the study period as described above. Although the rate of infusion of E2 in different animals was similar, there was marked variability in the plasma concentrations of estrogens achieved; therefore, the data were analyzed as the natural logarithm of the plasma E2 concentration. A similar variation in plasma E2 was observed in individual animals studied longitudinally. As illustrated in Figure 1, plasma levels of nonconjugated E2 in treated fetuses rose nearly 200-fold soon after the E2 infusion was started, increasing from a mean of $0.045 \pm 0.001 \mathrm{ng} / \mathrm{ml}$ pre-E2 treatment to $7.45 \pm 5.31$ $\mathrm{ng} / \mathrm{ml}(p<0.01)$ at $116-120$ days of gestation, and remained unchanged thereafter. In contrast, plasma E2 levels in control fetuses remained less than $0.06 \mathrm{ng} / \mathrm{ml}$ throughout the study period and were significantly lower than values in treated animals $(p<0.05)$. Plasma levels of unconjugated E1 (Fig. 2) also were elevated in treated fetuses, rising from $108 \pm 16$ to $344 \pm 62 \mathrm{pg} /$ $\mathrm{ml}$ by $111-115$ days of gestation $(p<0.05)$, and remained relatively unchanged thereafter. Because the variability in these measurements was quite large, likely reflective of the variable conversion of E2 to E1 by the fetus (15), values were not significantly different after 116 days of gestation even though they remained elevated. There were no significant alterations of plasma E1 levels in the control fetuses.

We also examined the effect of E2 infusion on fetal plasma

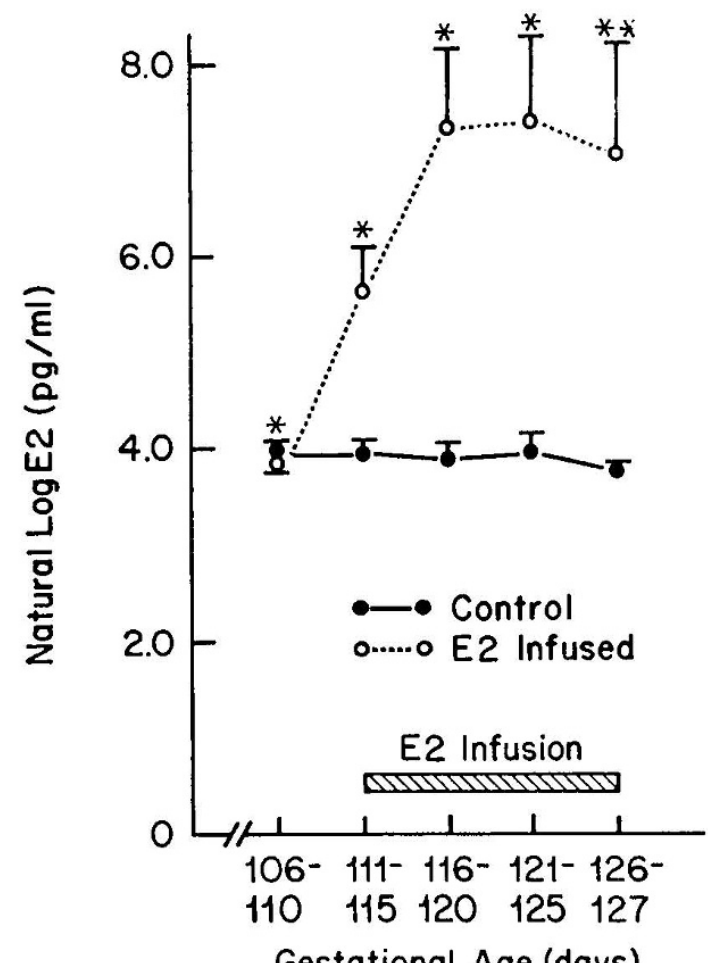

Fig. 1. Plasma concentrations of unconjugated E2 in fetal sheep infused with saline $(\longrightarrow)$ or E2 $\left(\mathrm{O}_{---}\right)$) from 111 to 127 days of gestation. The data are expressed as the natural logarithm of the $\mathrm{pg} / \mathrm{ml}$ of plasma E2. The period of E2 infusion is shown by the hatched bar. Asterisks indicate a significant difference $(p<0.05)$ between saline- $(n$ $=5$ ) and E2-infused animals $(n=7)$. Values are the mean $\pm \mathrm{SE}$.

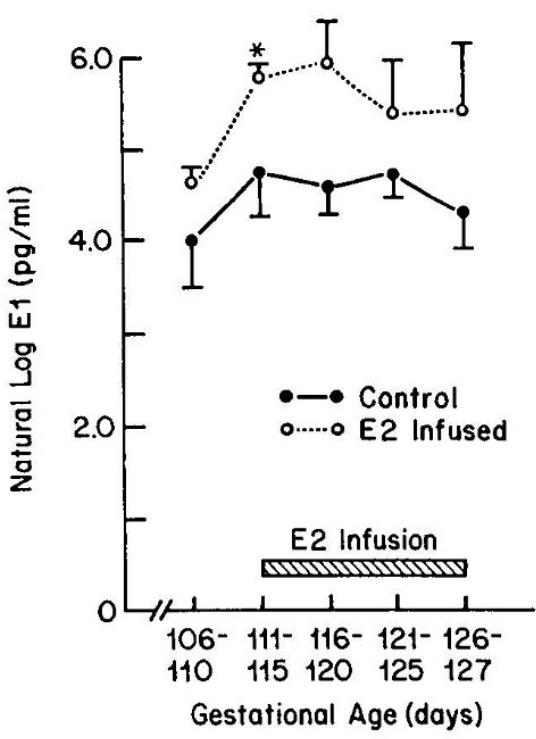

Fig. 2. Plasma concentrations of unconjugated $\mathrm{El}$ in fetal sheep infused with saline $(\longrightarrow, n=5)$ or estradiol (E2) (O--O, $n=7)$. The data are expressed as the natural logarithm of the $\mathrm{pg} / \mathrm{ml}$ of plasma E1. The period of E2 infusion is shown by the hatched bar. Asterisks indicate a significant difference $(p<0.05)$ between saline- and E2infused animals. Values are the mean $\pm S E$.

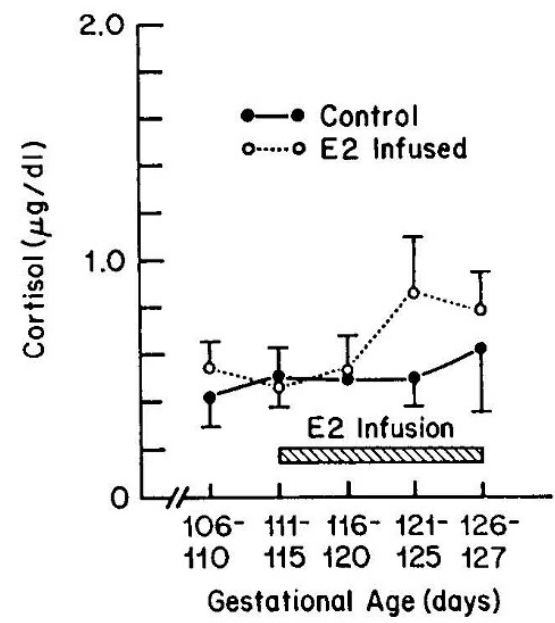

Fig. 3. Plasma concentrations of cortisol $(\mu \mathrm{g} / \mathrm{dl})$ in fetal lambs infused with saline $(\mathrm{n}=5, \longrightarrow)$ or $\mathrm{E} 2(n=7, \mathrm{O}--\mathrm{O})$. The period of $\mathrm{E} 2$ infusion is indicated by the hatched bar. Values are the mean $\pm \mathrm{SE}$.

levels of cortisol (Fig. 3), a hormone that has been shown to stimulate fetal lung maturation $(29,30)$ in this species. Although there was a tendency for plasma concentrations of cortisol to rise more rapidly near the end of the study period in the E2-infused fetuses $(n=7)$, this did not achieve statistical significance $(p>$ 0.05 ) and values were not significantly different from values for control fetuses $(n=5)$. Cortisol levels in the control fetuses also were not significantly changed throughout the period of study.

Phospholipids. The ratio of acetone-precipitated $\mathrm{PC} / \mathrm{S}$ in tracheal effluent varied in both E2-infused and control fetus during the gestational period studied (Fig. 4). However, none of these changes was significant. Furthermore, the PC/S values in E2infused and control groups were not significantly different from each other throughout the experiment and were not correlated with the plasma levels of $\mathrm{E} 2$ or $\mathrm{E} 1$.

As with the PC/S values, the flux of acetone-precipitable PC in tracheal fluid was also variable, particularly early in gestation (Fig. 5). Variability in PC flux also occurred in individual animals 


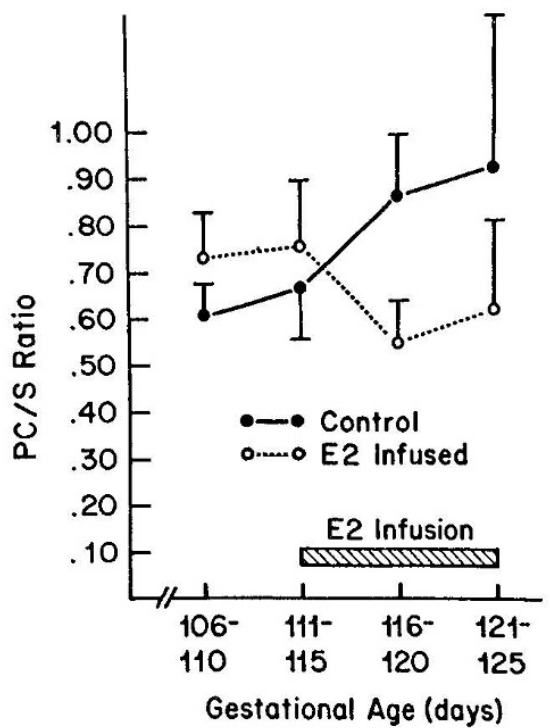

Fig. 4. The $\mathrm{PC} / \mathrm{S}$ ratio in tracheal fluid collected from saline$(\longrightarrow, n=6)$ or estradiol (E2)-infused animals (O---O, $n=8$ ). The period of infusion is indicated by the hatched bar. Values are the mean $\pm \mathrm{SE}$.

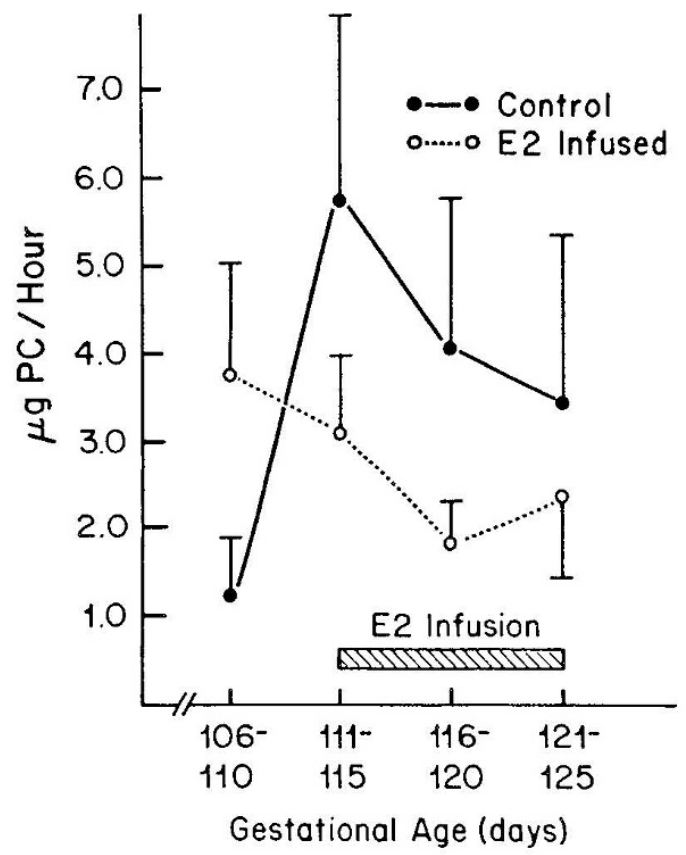

Fig. 5. The phosphatidylcholine flux ( $\mu \mathrm{g} \mathrm{PC} / \mathrm{h})$ in tracheal fluid collected from saline- $(\bullet, n=6)$ or E2-infused animals $(\mathrm{O}--\mathrm{O}, n=$ 8 ). The infusion period is indicated by the hatched bar. Values are the mean $\pm \mathrm{SE}$

studied longitudinally. No significant changes in PC flux occurred during the study period and no significant differences between the E2 group and the control group were found. The $\mathrm{PC} / \mathrm{S}$ levels were not significantly correlated with either E1 or E2 plasma levels. There was also no observed effect of E2treatment on the volume of tracheal fluid collected.

The phospholipid content of fetal lung tissues collected after the infusion period in three treated and three control fetuses are shown in Table 1. The total phospholipid per mg protein, total PC per mg protein, and the DSPC to total PC ratio were unchanged by E2 treatment of the fetus.

Morphology. We used light microscopic morphometric techniques to examine sections of lung tissues obtained from six of the control and five of the estrogen-iniused fetuses included in the study. Slides were masked, coded, and evaluated by two investigators. No consistent effect of estrogen-infusion on the volume density occupied by lumen, epithelium, connective tissue, or blood vessels was evident (Table 2). The lung tissue was relatively mature morphologically on day 127 of gestation as has been described previously (31). Some of the fetal lung tissue samples were thin sectioned and examined by electron microscopy. The fetal lung tissues contained differentiated type II cells; however, no consistent ultrastructural differences between lung tissue from control and E2-infused fetuses were observed (data not shown).

\section{DISCUSSION}

Estrogen has been shown to stimulate fetal lung maturation in the rat and rabbit species (7-11). In one study, this effect was shown to be direct when estrogen was added to explants of rat fetal lung maintained in serum-free media (10). However, in that in vitro study, the effect of estrogen was not as great as had been observed previously in in vivo studies (7-9). In addition, very high concentrations of estrogen were required to obtain stimulatory effects. Since transplacental transfer of estrogen from the maternal to the fetal compartment is limited (12) and fetal metabolism of estrogen is rapid (13-15), and since fetal estrogen concentrations were not determined in prior in vivo studies, the results of those studies may have reflected a mechanism other than that mediated directly by estrogen. Therefore, we utilized the chronically instrumented fetal sheep model in which estrogen could be infused directly into the fetal circulation. In this manner, we were able to study the effects of prolonged elevations in plasma concentrations of unconjugated estrogen on fetal lung maturation in vivo at a time prior to the natural occurrence of fetal lung maturation in the sheep $(16,17)$.

To utilize the model effectively, we examined several parameters of fetal lung maturation, i.e. the rate of surfactant secretion into tracheal fluid, the tracheal fluid ratio of acetone-precipitable $\mathrm{PC} / \mathrm{S}$, lung tissue phospholipid content, and lung morphology. We determined that elevated plasma estrogen levels had no effect on any of these factors. However, it is possible that, because of the variability in PC/S ratios and in PC flux, a small effect of estrogen on these parameters may have been observed.

The lung of the sheep fetus has been shown to be responsive to glucocorticoids $(30,32,33)$. It is of interest that the estrogen infusion was associated with a slight increase in plasma cortisol

Table 1. Phospholipid of lung tissues from control and estrogeninfused fetuses (mean $\pm S E$ )

\begin{tabular}{|c|c|c|c|}
\hline & & $\begin{array}{l}\text { Control } \\
(n=3)\end{array}$ & $\begin{array}{l}\text { Estrogen-infused } \\
\quad(n=3)\end{array}$ \\
\hline I & $\begin{array}{l}\text { Total phospholipid } \\
\text { (nmol } \mathrm{PO}_{4} / \mathrm{mg} \\
\text { protein) }\end{array}$ & $98.9 \pm 14.9$ & $120.5 \pm 21.1$ \\
\hline II & $\begin{array}{l}\text { Total PC (nmol } \\
\mathrm{PO}_{4} / \text { mg protein) }\end{array}$ & $61.7 \pm 13.7$ & $60.0 \pm 10.8$ \\
\hline III & $\begin{array}{l}\text { \% DSPC of total } \\
\text { PC }\end{array}$ & $43.3 \pm 4.6$ & $39.7 \pm 3.9$ \\
\hline
\end{tabular}

Table 2. Morphometry of fetal sheep lung tissue (mean \pm SE)

\begin{tabular}{lcc}
\hline & \multicolumn{2}{c}{ Volume density (\%) } \\
\cline { 2 - 3 } \multicolumn{1}{c}{ Parameter } & $\begin{array}{c}\text { Control } \\
(n=6)\end{array}$ & $\begin{array}{c}\text { Estrogen-infused } \\
(n=5)\end{array}$ \\
\hline Lumen & $42.6 \pm 10.9$ & $42.8 \pm 8.5$ \\
Epithelium & $19.5 \pm 4.6$ & $20.7 \pm 3.7$ \\
Connective tissue & $28.2 \pm 8.4$ & $28.7 \pm 7.7$ \\
Blood vessels & $9.8 \pm 1.5$ & $8.1 \pm 3.1$ \\
\hline
\end{tabular}


levels; however, this was not associated with accelerated fetal lung maturation. The slight increase in cortisol levels we observed in the E2-infused fetuses may not have been of sufficient magnitude to stimulate lung maturation. Furthermore, the fetal sheep lung may require other hormones, in addition to glucocorticoids, to achieve lung differentiation; this is supported by the observation that the infusion of exogenous glucocorticoids into the sheep fetus will not reverse the inhibitory effects of hypophysectomy on fetal lung maturation (32).

Normal values for fetal lamb tracheal surfactant flux during this interval of gestation have been reported by Platzker et al. (30) and Taeusch et al. (33). Direct comparisons of our data and that of the previous reports are difficult because Platzker et al. (30) measured surface activity, then converted that biophysical parameter to a DSPC concentration, and Taeusch et al. (33) measured DSPC concentration. If ones uses the assumption of Platzker et al. (30) for DSPC concentration and further assumes that acetone-precipitated PC is enriched with DSPC (approximately $75 \%$ ), then our flux results are in reasonable agreement. The apparent decrease in flux over gestation seen in our data is not statistically or biologically significant and always remained within the normal range described in these previous studies.

Our findings concerning the effects of estrogen on surfactant production in the fetal sheep are not in agreement with the findings of investigators who have used the fetal rat or rabbit. The reasons for this discrepancy are not clear. We infused estrogen at a stage in fetal sheep lung maturation that is considered comparable to the stages of fetal lung development previously studied in the rat and rabbit and is prior to morphological and biochemical maturation in the sheep fetus $(16,17,31)$. The plasma levels of estrogen that we achieved in the E2-infused animals are about two orders of magnitude less than the $10^{-5} \mathrm{M}$ dose that was effective in the rat in vitro studies; however, it is difficult to imagine a physiological situation in which fetal plasma estrogen would reach such high levels. In fact, in the sheep fetus, plasma concentrations of unconjugated E2 and E1 do not attain the levels attained in these experiments until the onset of parturition, values reported to range from 75 to $>400$ $\mathrm{pg} / \mathrm{ml}(19)$. It is possible that in the sheep fetus receptors for estrogen are not present during the time period we studied or that estrogen acts via the release of or in association with other hormones, e.g. prolactin, which have been associated with changes in lung maturation.

Taeusch et al. (33) reported that the response of the fetal sheep lung to dexamethasone infusion was variable, with some fetuses showing no response in surfactant production while others showed a marked response, which in some cases appeared to be transient. Examination of the results from individual fetuses in our study did not indicate that a similar phenomenon occurred. Furthermore, the data of Taeusch et al. (33) are suggestive that the grouping of our data into 5-day blocks would not keep us from identifying a significant but transient effect, since the effects observed in their study were at least 5 days in duration.

In this study, we have produced a substantial increase in plasma concentrations of unconjugated E2 and E1 in the fetal blood for a 2-wk period. Nevertheless, in this intact animal model, we were unable to detect any effect of elevated plasma estrogens on a number of different parameters of lung maturation. We therefore conclude that, in the sheep, estrogen does not stimulate fetal lung maturation over the period prior to 128 days of gestation. The possibility remains, however, that estrogen may exert stimulatory effects on lung maturation later in gestation.

\section{REFERENCES}

1. Avery ME, Mead J 1959 Surface properties in relation to atelectasis and hyaline membrane disease. Am J Dis Child 97:517-523
2. Ballard PL 1982 Hormonal aspects of fetal lung development In: Farrell PM (ed) Lung Development: Biological and Chemical Perspectives. Academic Press, New York, pp 205-253

3. Shutt DA, Smith ID, Shearman RP 1974 Oestrone, oestradiol-17 $\beta$ and oestrio levels in human foetal plasma during gestation and at term. J Endocrinol 60:333-341

4. Parker CR Jr, Illingworth DR, Bissonnette J, Carr BR 1986 Endocrine changes during pregnancy in a patient with homozygous hypobetalipoproteinemia. N Engl J Med 314:557-560

5. Dickey RP, Robertson AF 1969 Newborn estrogen secretion. Am J Obstet Gynecol 140:551-555

6. Stovall WS, Dashow EE, Read JA 1985 Serum unconjugated estriol level as a predictor of pulmonary maturity. Am J Obstet Gynecol 153:568-569

7. Khosla SS, Rooney SA 1979 Stimulation of fetal lung surfactant production by administration of $17 \beta$-estradiol to the maternal rabbit. Am J Obstet Gynecol 133:213-216

8. Khosla SS, Gobran LI, Rooney SA 1980 Stimulation of phosphatidylcholine synthesis by $17 \beta$-estradiol in fetal rabbit lung. Biochim Biophys Acta 617:282-290

9. Khosla SS, Walker-Smith GJ, Parks PA, Rooney SA 1981 Effects of estrogen on fetal rabbit lung maturation: Morphological and biochemical studies. Pediatr Res 15:1274-1281

10. Gross I, Wilson CM, Ingleson LD, Brehier A, Rooney SA 1979 The influence of hormones on the biochemical development of fetal lung in organ culture. I. Estrogen. Biochim Biophys Acta 575:375-383

11. Thuresson-Klein A, Moawad AH, Hedqvist P 1985 Estrogen stimulates formation of lamellar bodies and release of surfactant in the rat fetal lung. Am J Obstet Gynecol 151:506-514

12. Walsh SW, McCarthy MS 1981 Selective placental secretion of estrogens into fetal and maternal circulations. Endocrinology 109:2152-2159

13. Hill DE, Slikker W Jr, Helton ED, Lipe GW, Newport GD, Szisak TJ, Bailey JR 1980 Transplacental pharmacokinetics and metabolism of diethylstilbesterol and $17 \beta$-estradiol in the pregnant Rhesus monkey. J Clin Endocrinol Metabl 50:811-818

14. Levitz M, Condon GP, Dancis J 1961 Sulfurylation of estrogens by the human fetus. Endocrinology 68:825-830

15. Rosenfeld CR, Naden RP 1981 Removal of exogenous estrogen by the ovine fetal placental unit. Proceedings of the 63rd Annual Meeting of the Endocrine Society, p 116(abstr)

16. Mescher EJ, Platzker ACG, Ballard PL, Kitterman JA, Clements JA, Tooley WH 1975 Ontogeny of tracheal fluid, pulmonary surfactant, and plasma corticoids in the fetal lamb. J Appl Physiol 39:1017-1021

17. Rosenfeld CR, Andujo O, Johnston JM, Jimenez JM 1980 Phosphatidic acid phosphohydrolase and phospholipids in tracheal and amniotic fluids during normal ovine pregnancy. Pediatr Res 14:891-893

18. Rosenfeld CR, Worley RJ, Milewich L, Gant NF, Parker CR Jr 1980 Ovine fetoplacental sulfoconjugation and aromatization of dehydroepiandrosterone. Endocrinology 106:1971-1979

19. Challis JRG 1971 Sharp increase in free circulating estrogens immediately before parturition in sheep. Nature 229:208

20. Parker CR Jr, Ellegood JO, Mahesh VB 1975 Methods for multiple steroid radioimmunoassay. J Steroid Biochem 6:1-8

21. Gomez-Sanchez C, Milewich L, Holland OB 1977 Radioiodinated derivatives for steroid radioimmunoassay. Application to the radioimmunoassay of cortisol. J Lab Clin Med 89:902-909

22. Lowry OH, Rosebrough NJ, Farr AL, Randall RJ 1951 Protein measurement with the Folin phenol reagent. J Biol Chem 193:265-275

23. Bligh EC, Dyer WJ 1959 A rapid method of total lipid extraction and purification. Can J Biochem Physiol 37:911-917

24. Mason RJ, Nellenbogen J, Clements JA 1976 Isolation of disaturated phosphatidylcholine with osmium tetroxide. J Lipid Res 17:281-284

25. Bartlett GR 1959 Phosphorus assay in column chromatography. J Biol Chem 234:466-471

26. Gluck L, Chez RA, Kulovich MV, Hutchinson DL, Niemann WH 1974 Comparison of phospholipid indicators of fetal lung maturity in the amniotic fluid of the monkey and baboon. Am J Obstet Gynecol 120:524-530

27. Snyder JM, Johnston JM, Mendelson CR 1981 Differentiation of type II cells of human fetal lung in vitro. Cell Tissue Res 22:17-25

28. Zar JH 1984 Biostatistical Analysis. Prentice Hall, Englewood Cliffs, NJ, pp. $190-191$

29. Liggins GC 1969 Premature delivery of foetal lambs infused with glucocorticoids. J Endocrinol 45:515-523

30. Platzker ACG, Kitterman JA, Mescher EJ, Clements JA, Tooley WH 1975 Surfactant in the lung and tracheal fluid of the fetal lamb and acceleration of its appearance by dexamethasone. Pediatrics 56:554-561

31. Kikkawa Y, Motoyama EK, Cook CD 1965 The ultrastructure of the lungs of lambs. Am J Pathol 47:877-903

32. Kitterman J, Liggins GC, Campos G, Forster C, Creasy R 1979 Hormonal factors in fetal lung maturation. Pediatr Res 13:537(abstr)

33. Taeusch HW Jr, Brown ER, Torday JS, Nielsen HC 1981 Magnitude and duration of lung response to dexamethasone in fetal sheep. Am J Obstet Gynecol 140:452-455 